\title{
I OLIMPÍADA DE SUSTENTABILIDADE DO SUL DA BAHIA
}

Marcelo Soares Teles Santos - marcelostsantos@ufsb.edu.br

Julia Carvalho Dias De Gouvêa - juliagouvea@ufsb.edu.br

Fernando Silva dos Santos - fernando_silva.18@hotmail.com

Nayara Alves Rocha - nayrocha01@gmail.com

Filipe de Oliveira Santana - lipeoliver_2@hotmail.com

Universidade Federal do Sul da Bahia, Centro de Formação em Tecnociências e Inovação

Rod. Ilhéus - Vitória da Conquista, s/n, km 39, BR 415, Ferradas

CEP 45613-204 - Itabuna - Bahia

Resumo: A I Olimpíada de Sustentabilidade do Sul da Bahia teve como objetivo geral divulgação e popularização de Ciência e Tecnologia para estudantes do Ensino Básico do Sul da Bahia, especialmente nos municípios atendidos pelos Colégios Universitários da UFSB, como forma de estimulá-los ao estudo do campo das Ciências a partir de um tema interdisciplinar relevante aos problemas contemporâneos, a Sustentabilidade. As atividades foram realizadas em três fases: i) avaliação teórica nas escolas, que serviu para selecionar as equipes de estudantes das escolas para as fases realizadas na Universidade; ii) atividade experimental na Universidade, onde os estudantes conheceram práticas e tecnologias da sustentabilidade a partir de uma casa sustentável; e iii) gincana colaborativa na Universidade, onde os estudantes participaram de dinâmica em equipe para capacitação $e$ conscientização ambiental. O evento contou com a participação 312 estudantes de 10 escolas na primeira fase; nessa fase, cinco escolas tiveram suas equipes de cinco estudantes selecionadas para as fases na Universidade. Na segunda e na terceira fases, os vencedores da Olimpíada foram definidos em função das pontuações obtidas nas atividades experimentais e práticas desenvolvidas na Universidade. Nota-se que as fases realizadas na Universidade serviram para estimular a criatividade $e$ a inventividade de alunos $e$ professores, o despertar de vocações científicas e os vínculos de cooperação entre equipes de estudantes e professores.

Palavras-chave: Ensino Básico. Tecnologia Educacional. Olimpíada Científica.

\section{INTRODUÇÃO}

As olimpíadas científicas são competições para estudantes do ensino fundamental ou médio, realizadas com o objetivo de incentivar e encontrar talentos nas diversas áreas do conhecimento. Nas Ciências básicas, especificamente, destacam-se nacionalmente a Olimpíada Brasileira de Física (http://www.sbfisica.org.br/v1/olimpiada/2020/), a Olimpíada Brasileira de Química (http://www.obquimica.org/), e a Olimpíada Nacional de Ciências (https://onciencias.org/). As olimpíadas são realizadas em etapas, as quais podem ter diferentes formatos, como provas teóricas, experimentais e práticas.

A "I Olimpíada de Sustentabilidade do Sul da Bahia" teve como Objetivo Geral despertar e estimular o interesse de estudantes do ensino básico da região Sul da Bahia ao estudo do Campo das Ciências, a partir de atividades didáticas relacionados com o tema interdisciplinar do evento, a Sustentabilidade - transversal às Ciências da Natureza e de extrema importância aos problemas contemporâneos, especialmente no Sul da Bahia. 
Para atingir os objetivos, a Olimpíada foi realizada em três fases: i) avaliação teórica nas escolas, que serviu para selecionar estudantes e formar as equipes de cada escola para participação nas fases presenciais na Universidade; ii) atividade experimental na Universidade, onde os estudantes conheceram práticas e tecnologias da sustentabilidade em uma casa com práticas e tecnologias sustentáveis; e iii) gincana colaborativa na Universidade, onde os estudantes participaram de dinâmica em equipe para capacitação e conscientização ambiental.

A casa sustentável foi implantada no Campus da UFSB em um Ciclo de Oficinas Pedagógicas que teve como objetivo implantar a Casa Sustentável, capacitar estudantes sobre as práticas e tecnologias sustentáveis e formar estudantes monitores para atuarem na Olimpíada. Conceitualmente, a Casa Sustentável consistiu na requalificação de espaços e processos de uma casa convencional com a inserção de práticas e tecnologias relacionadas à gestão sustentável de água, energia, resíduos e produção de alimentos.

Nesse caso, as fases presenciais da Olimpíada permitiram, além da imersão dos estudantes em ambientes de ensino-aprendizagem de ciências baseados em rotinas reais de práticas e tecnologias sustentáveis, o desenvolvimento nos estudantes de habilidades como percepção, conscientização e sensibilização ambiental. Essa imersão permitiu a abordados temas importantes para a atualidade, tais como uso racional de água e energia, geração de resíduos sólidos, produção e consumo de alimentos orgânicos, preservação ambiental, entre outros.

\section{A CASA SUSTENTÁVEL}

As fases presenciais da Olimpíada, na Universidade, foram realizadas nas instalações de uma casa sustentável, onde os estudantes tiveram contato e foram inseridos no contexto de práticas e tecnologias da Sustentabilidade. Para fornecer o embasamento teórico necessário ao entendimento dessas fases da Olimpíada, serão apresentados, a seguir, o modelo conceitual da Casa Sustentável da UFSB e as práticas e tecnologias nela implantadas.

Conceitualmente, a Casa Sustentável consistiu na requalificação de espaços e processos de uma casa convencional visando o seu funcionamento dentro dos princípios atuais de sustentabilidade, ou seja, a transformação de uma "casa convencional" em uma "casa sustentável". Assim, a Casa Sustentável é operacionalizada com práticas cotidianas sustentáveis, tais como (CIANCIARDI, 2014; CORBELLA \& YANNAS, 2009; CUSTÓDIO, 2013; DAVIS, 2016; DOURADO et al., 2015; MANCUSO \& SANTOS, 2003; KEELER \& BURKE, 2010; KOWALTOWSKI, 2011; TOMAZ, 2003; VILLALVA, 2015):

- Aproveitamento de iluminação e ventilação natural com adoção de elementos da “Arquitetura Sustentável".

- Coleta, reutilização, reciclagem, tratamento e disposição final de resíduos sólidos.

- Coleta e aproveitamento de água de chuva.

- Separação, tratamento e reuso de águas residuárias e esgotos domésticos.

- Uso de energias limpas (solar, eólica, biogás).

- Adoção de técnicas de agricultura familiar (Agroecologia e Produção Orgânica).

- Definição de áreas de Lazer e Esporte para a Qualidade de Vida.

Essa requalificação envolveu a gestão integrada das práticas sustentáveis, que consiste em sistematizar a integração dos diferentes processos da Casa: por exemplo, para a produção de alimentos orgânicos: i) a horta caseira é irrigada com água de um reservatório abastecido por um sistema de coleta de água de chuva; ii) o sistema de água de chuva é composto por um 
bombeamento por energia solar fotovoltaica para elevação e armazenamento da água; iii) a coleta seletiva de resíduos sólidos fornece os recipientes (vasos) para a "horta em vasos" e os resíduos orgânicos para a compostagem (adubo para o solo); iv) o tratamento de águas residuárias fornece água adicional para irrigação da horta (além da limpeza de pisos externos e abastecimento de vasos sanitários).

A requalificação da casa convencional foi realizada no Pavilhão de Serviços da UFSB, denominado "Copa", considerado um espaço na UFSB que reúne as condições adequadas ao pleno funcionamento de um protótipo de uma casa sustentável, em termos de espaços físicos construídos (cozinha, banheiros masculino e feminino, salas), equipamentos e eletrodomésticos em pleno uso (geladeira, computadores, lâmpadas, microondas, arcondicionado, etc.), usuários bem definidos nas instalações, cobertura mista em laje e telhas para instalação dos equipamentos, e localização estratégica nas proximidades do pavilhão de aulas.

No âmbito da Casa Sustentável da UFSB foram adquiridos kits experimentais relacionados com o uso sustentável de água, energia, resíduos e produção de alimentos, descritos a seguir.

- Biodigestor - equipamento para tratamento orgânico de esgoto domiciliar de uma residência com até 5 pessoas;

- Sistema coleta de água de chuva - composto por calha, tubulações e conexões, dispositivo para separar a "primeira água de chuva", e reservatório de armazenamento de água de chuva;

- Sistema de Energia Solar - composto por 3 placas fotovoltaicas, controlador de carga, banco de baterias com 3 baterias, inversor e conexões;

- Sistema de Energia Eólica - conjunto composto por aerogerador residencial, controlador de carga, bateria e inversor;

- Toldo para coleta seletiva - toldo de dimensões $3 \times 3$ para separação de materiais da coleta seletiva.

\section{METODOLOGIA}

A Olimpíada foi realizada em três fases: i) avaliação teórica nas escolas, ii) atividade experimental na Universidade; e iii) gincana colaborativa na Universidade. A primeira fase nas escolas teve com objetivo avaliar o conhecimento dos estudantes e formar as equipes representantes de cada escola. A segunda fase foi na Universidade, onde os estudantes conheceram práticas e tecnologias da sustentabilidade de uma casa com práticas e tecnologias sustentáveis. A terceira fase também foi na UFSB, onde os estudantes participaram de dinâmica em equipe para capacitação e conscientização ambiental.

- Primeira fase da Olimpíada: Avaliação Teórica nas Escolas - essa fase foi realizada nas escolas participantes com a coordenação de um professor de Ciências da Natureza da escola, para estudantes de duas modalidades: Ensino Fundamental $\left(9^{\circ}\right.$ ano) e Ensino Médio ( $3^{\circ}$ ano). Consistiu em avaliação teórica escrita composta por 8 questões objetivas de múltipla escolha relacionadas com as áreas de Biologia, Física e Química. As questões foram todas de nível básico, com objetivo de destacar os estudantes com melhor conhecimento geral dos conceituais fundamentais das Ciências envolvidos com a sustentabilidade. A avaliação teórica foi eliminatória e classificatória para as etapas posteriores na Universidade, da seguinte forma: i) os estudantes com as 5 maiores notas em cada escola formaram as equipes das escolas; e ii) as 5 equipes com os maiores 
somatórios das notas de seus integrantes foram os finalistas da Olimpíada, e participaram das fases presenciais na Universidade.

- Segunda fase da Olimpíada: Avaliação Experimental na Universidade - essa fase consistiu na visita orientada dos estudantes à Casa Sustentável da UFSB, onde foram imersos em ambiente de ensino-aprendizagem baseados em rotinas reais de práticas e tecnologias sustentáveis de uma casa. As atividades realizadas nessa fase ocorreram em três momentos: i) apresentação da Olimpíada e da Casa Sustentável; ii) visita orientada à Casa Sustentável, onde os estudantes participaram de exposições temáticas sobre as práticas e tecnologias presentes na casa; e iii) avaliação de Ciências, composta por questões objetivas de múltipla escolha das áreas de Biologia, Física e Química contextualizadas com as práticas e tecnologias expostas.

- Terceira fase da Olimpíada: Gincana Colaborativa na Universidade - essa fase teve como objetivo desenvolver nos estudantes habilidades como percepção, conscientização e sensibilização ambiental. As atividades ocorreram em 2 momentos: i) capacitação ambiental das equipes, através de palestras técnicas sobre o tema poluição ambiental, para fornecer conceitos básicos necessários ao desenvolvimento da gincana; ii) dinâmica de grupo, para estimular e mostrar a importância do ambiente colaborativo para a sustentabilidade do planeta; e iii) realização da gincana colaborativa, cujas missões foram estabelecidas para que os estudantes pudessem procurar e identificar problemas de poluição ambiental inseridos no território do Campus da UFSB, investigar e sugerir suas causas, e propor soluções tecnicamente coerentes para o problema.

Vale destacar que nas fases presenciais da Olimpíada foram utilizadas metodologias ativas para a consolidação dos aprendizados adquiridos nas fases e nos momentos anteriores. A segunda fase (avaliação experimental) utilizou práticas e tecnologias da sustentabilidade presentes em uma casa sustentável para contextualizar o ensino de ciências; na terceira fase (gincana colaborativa), a dinâmica em grupo utilizou a metodologia de brincadeiras sociais (JUNIOR, 2010), enquanto a gincana aplicou algumas etapas da estratégia de Aprendizagem Baseada em Problema (ABProb), na qual o problema é utilizado como incentivo ao aprendizado e busca-se uma atmosfera colaborativa para a elaboração do conhecimento (BARBOSA \& MOURA, 2014).

\section{RESULTADOS}

\subsection{Resultados da $1^{\circ}$ Fase da Olimpíada}

A primeira fase da Olimpíada contou com a participação de dez escolas de ensino básico da região, sendo cinco do Ensino Fundamental e cinco do Ensino Médio, localizadas nos municípios da Rede CUNI (Itabuna, Ilhéus, Ibicaraí e Coaraci), em um total de 312 estudantes que fizeram a avaliação. Desses, foram destacados: os 50 estudantes que formaram as equipes de 5 estudantes das 10 escolas participantes; e 25 estudantes das 5 equipes finalistas da Olimpíada, que participaram das fases presenciais na Universidade.

A Figura 1 mostra as estatísticas do rendimento das escolas participantes (mantendo o anonimato das escolas), em função da turma (número total de estudantes) e da equipe representante (5 estudantes com as maiores notas). Na primeira fase: os 312 estudantes participantes tiveram notas com média de 5,91, desvio padrão de 2,09, mínimo de 1,25 e máximo de 10,00; os 50 estudantes representantes das escolas tiveram notas com média de 8,65, desvio padrão de 1,23, mínimo de 6,25 e máximo de 10,00 . 
Figura 1 - Desempenho das escolas (turmas e equipes) participantes na primeira fase da Olimpíada, em função da média das notas.

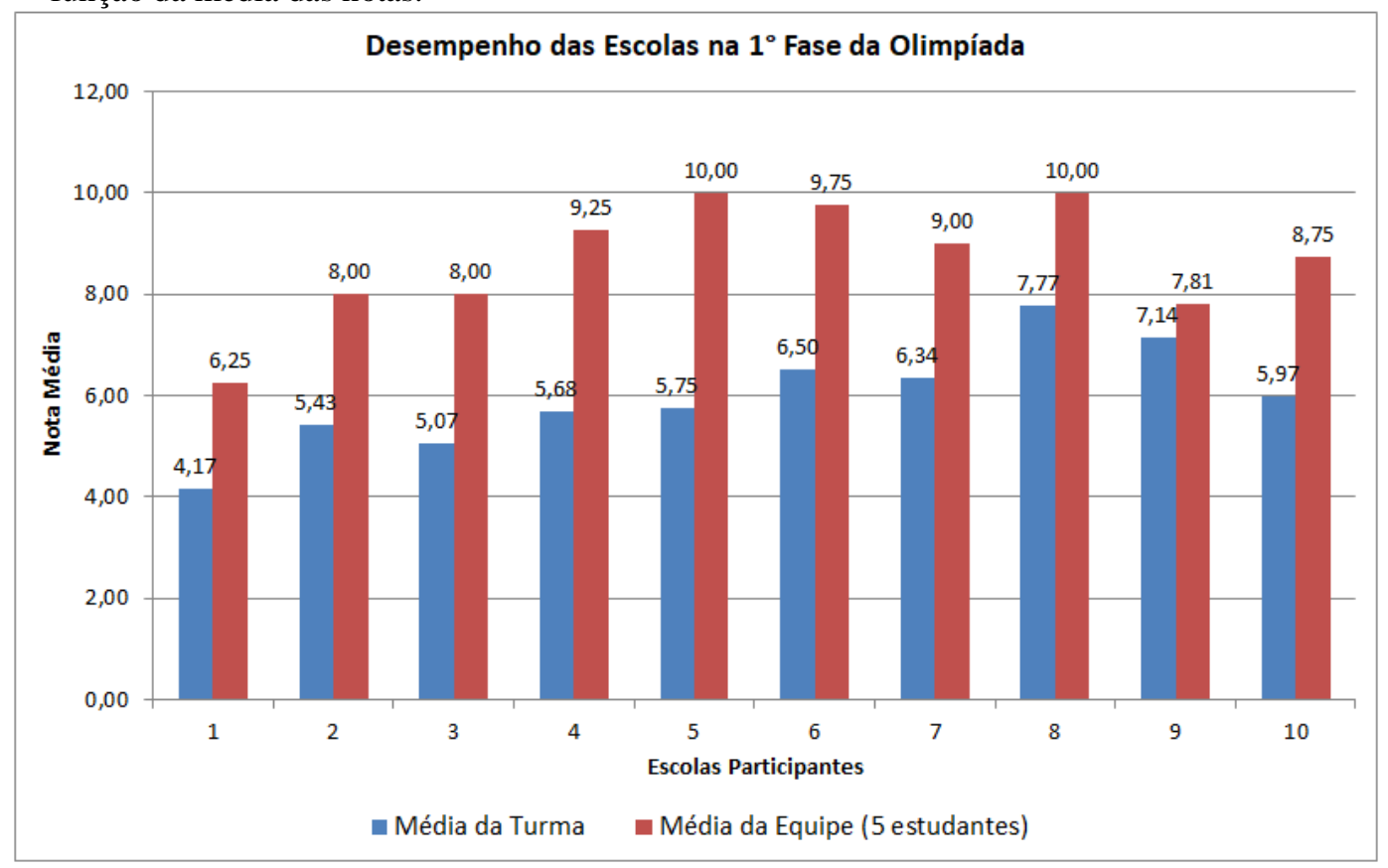

Fonte: autores.

\subsection{Resultados da $2^{\circ}$ Fase da Olimpíada}

$\mathrm{Na}$ visita orientada à Casa Sustentável, estudantes monitores da UFSB realizaram exposições temáticas sobre as diversas práticas e tecnologias utilizadas na casa, a partir de pôsteres posicionados nos locais das instalações. A seguir são apresentados os temas e os objetivos das exposições realizadas na visita orientada à Casa Sustentável (apresentadas na Figura 2):

- Exposições 1, 2 e 3: Energias Limpas (Solar, Eólica e Biogás). Objetivos: apresentar o panorama do sistema energético nacional, as necessidades e vantagens do uso de energias limpas, os conceitos, os componentes e as formas de uso e aplicações dessas fontes de energia, com análise de custo-benefício.

- Exposições 4 e 5: Horta Sustentável e Composteira. Objetivo: apresentar os conceitos básicos da agricultura orgânica, tais como a relação planta-água-solo-atmosfera, os tipos de terras e adubos, a importância do aproveitamento de resíduos sólidos e água de chuva para a horta sustentável doméstica, assim como os princípios envolvidos com o processo de Compostagem e o desenvolvimento de uma Composteira.

- Exposição 6: Gerenciamento de Resíduos Sólidos. Objetivos: apresentar os aspectos técnicos e práticos relacionados com o gerenciamento de resíduos domésticos, com abordagem principal em consumo sustentável, não geração, redução, aproveitamento e tratamento de resíduos, especialmente na aplicação nas hortas em vasos.

- Exposição 7: Aproveitamento de Água de Chuva: Objetivos: apresentar a importância e os aspectos técnicos relacionados com o aproveitamento de água de chuva, especialmente nas hortas em vasos.

$\mathrm{Na}$ avaliação de Ciências, as práticas e tecnologias da Casa Sustentável foram utilizadas como contexto na criação de questões para avaliação de Biologia, Física e Química; assim, além de serem avaliados nos conceitos de Ciências, os estudantes foram capacitados quanto às 
tecnologias da sustentabilidade. A avaliação foi realizada de maneira dinâmica, da seguinte forma: um docente realizava a leitura de cada questão e disponibilizava 30 segundos para as equipes escreverem as respostas (A, B,C,D) em um formulário; depois desse tempo, os líderes das equipes foram orientados a expor as respostas, simultaneamente; o docente, então, apresentava a resposta correta. Dessa forma, em tempo real e de maneira progressiva, foram contabilizadas as quantidades de questões corretas e as pontuações das equipes.

Figura 2 - Fotografias das exposições dos pôsteres das tecnologias da Casa Sustentável: a) Energia Solar e Eólica; b) Composteira e Biodigestor; c) Horta Sustentável e Resíduos Sólidos Domiciliares; d) Coleta de Água de Chuva.

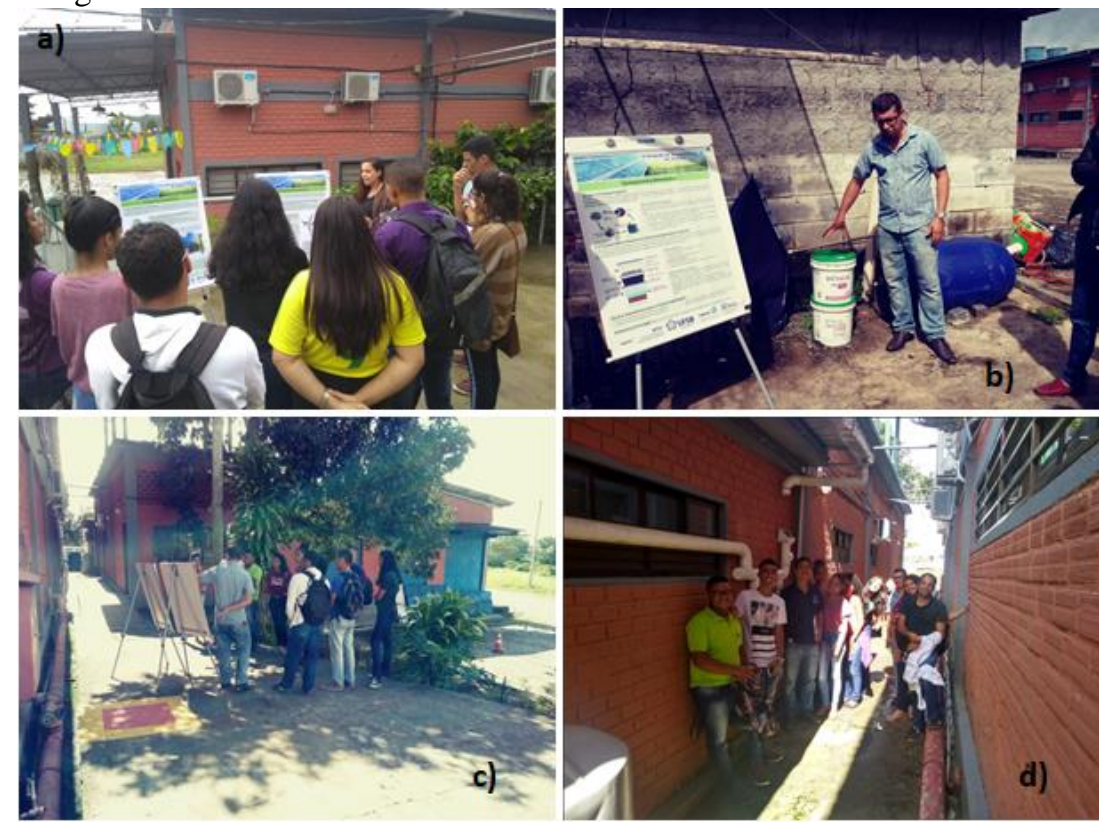

Fonte: autores.

\subsection{Resultados da $3^{\circ}$ Fase da Olimpíada}

Na capacitação ambiental, as palestras abordaram: os tipos de poluição ambiental e as formas de identificação, tais como desmatamento e despejo de resíduos sólidos e esgotos em margens de lagoas e rios; e as soluções técnicas mais simples adotadas para solução desses problemas, como gerenciamento de resíduos sólidos, coleta e tratamento de esgotos domésticos, e reflorestamento de nascentes e margens de lagoas e rios.

A dinâmica de grupo teve como objetivo aproximar os estudantes e criar um ambiente de harmonia e diversão, assim como estimular e mostrar a importância do ambiente colaborativo e do trabalho em equipe em prol da preservação do meio ambiente e da recuperação das áreas poluídas (para a sustentabilidade do planeta). Como consequência, a utopia de despertar os estudantes como cidadãos coletivos mais ativos socialmente e capazes de criar soluções sustentáveis coletivas para sua comunidade, bairro ou mesmo para a casa de sua família.

A gincana foi realizada de maneira sistemática a partir do desenvolvimento de três "missões":

- Missão 1 - Criar e apresentar um "grito de guarra" - as equipes foram orientadas a criar um grito de guarra que as representasse, contextualizado com o tema do evento, a Sustentabilidade.

- Missão 2 - Localizar problemas de poluição ambiental no Campus da Universidade - as equipes visitaram 3 locais do território do Campus previamente definidos e identificados 
com bandeiras coloridas, para tentar identificar possíveis problemas de poluição ambiental.

- Missão 3 - Propor soluções para um dos problemas ambientais encontrados - as esquipes escolheram e descreveram as propostas de estratégias de intervenção para a solução de 1 dos problemas ambientais encontrados.

- Missão 4 - Apresentar as propostas - as equipes apresentaram as propostas para as demais equipes e uma banca de professores.

A Figura 3 apresenta fotografias da realização da terceira etapa da Olimpíada. Na prática, cada equipe teve 10 minutos para se posicionar em cada uma das bandeiras, além de mais 10 minutos para escolha do problema a ser resolvido. As equipes não tiveram informação prévia sobre quais locais ocorreriam os problemas ambientais e quais seriam os problemas, sendo que, em apenas 2 bandeiras (de 3) ocorreram problemas ambientais: na bandeira 1, onde foram espalhados resíduos sólidos nas margens da lagoa (plásticos e papéis); e na bandeira 2 onde foi simulada tubulação de esgoto sendo despejado diretamente na Lagoa (a tubulação é de drenagem de águas pluviais).

Figura 3 - Fotografias da terceira etapa da Olimpíada: a) Palestra para capacitação ambiental; b) dinâmica de grupo para estimular o trabalho em equipe em prol da sustentabilidade do planeta; c) equipes de estudantes procurando os problemas ambientais das bandeiras; d) apresentação das equipes com as proposições de soluções dos problemas ambientais.

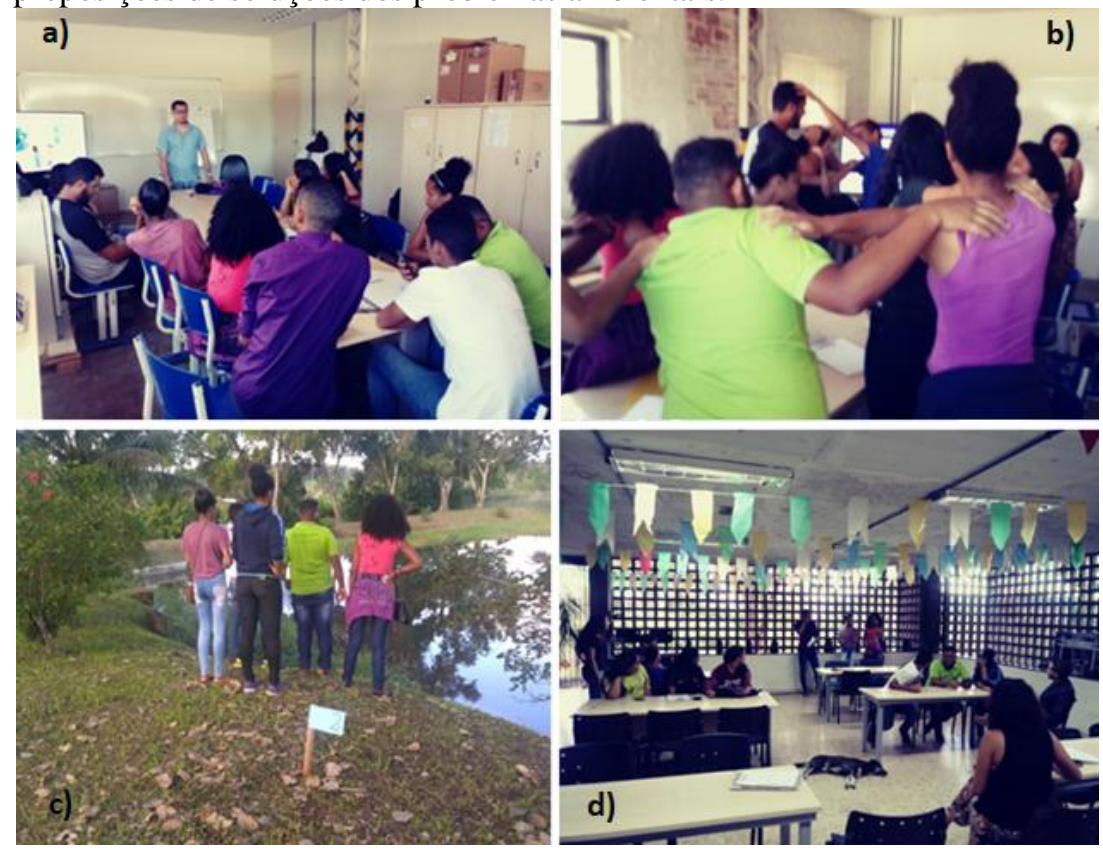

Fonte: autores.

\subsection{Pontuação, Classificação final e Premiações}

A Tabela 1 apresenta os resultados das etapas presenciais da olimpíada. Cada fase teve uma pontuação variando de 0 a 100 pontos, a qual foi contabilizada a partir de critérios definidos previamente em função das atividades programadas. As classificações e as premiações foram realizadas na modalidade de equipes, quando a pontuação de cada equipe foi o somatório das notas das etapas 2 e 3. Constituíram o pódio de vencedores, outo, prata e bronze, as equipes que tiverem os três maiores somatórios das notas, respectivamente. Os estudantes vencedores, seus professores orientadores, assim como as escolas vencedoras, receberam certificados de vencedores da Olimpíada, emitido pela UFSB. As escolas 
participantes e os estudantes participantes das fases presenciais na Universidade receberam certificados de participação na Olimpíada. As equipes vencedoras serão convidadas a apresentar os trabalhos da $3^{\circ}$ fase em forma de painéis em evento científico da UFSB, no qual receberão certificados de apresentação de trabalho em evento.

Tabela 1 - Pontuação das equipes participante da Olimpíada na fase presencial na UFSB

\begin{tabular}{c|c|c|c|c}
\hline & Etapa 02 & Etapa 03 & Total & Classificação \\
\hline Equipe 01 & 100 & 71 & 171 & $3^{\circ}$ \\
\hline Equipe 02 & 84 & 97 & 181 & $1^{\circ}$ \\
\hline Equipe 03 & 100 & 81 & 181 & $1^{\circ}$ \\
\hline Equipe 04 & 100 & 73 & 173 & $2^{\circ}$ \\
\hline Equipe 05 - ausente & - & - & - & - \\
\hline Fonte: autores.
\end{tabular}

\section{MECANISMOS DOS RESULTADOS}

Destacam-se os seguintes mecanismos de avaliação dos resultados:

- Divulgação e popularização de Ciências e Tecnologia - A Olimpíada contou com a participação efetiva de docentes e estudantes de 10 escolas de Ensino Básico da região, além do público interno da UFSB. Porém, a divulgação do evento alcançou um público ainda maior dentro das escolas participantes e, ainda, em outras escolas que, por motivos diversos, não puderam participar dessa edição do evento. Ainda, o evento teve abrangência regional com a inserção da Universidade nos municípios de Ilhéus, Itajuípe e Coaraci através dos CUNIs. A divulgação pós-evento contribuirá ainda mais para a divulgação e popularização da Ciência e tecnologia envolvidas com a Sustentabilidade.

- Avaliação do desempenho das escolas - os resultados da primeira fase geraram relatório com informações sobre o desempenho das escolas participantes, dados esses que serão de extrema importância nas tomadas de decisão quanto a políticas públicas voltadas à melhoria da educação. Esses resultados poderão estimular o desenvolvimento de programas ou projetos internos de aperfeiçoamento do Ensino de Ciências nas escolas. Ainda, a primeira fase identificou jovens talentos com potencial no estudo do Campo das Ciências, os quais participaram das etapas posteriores na Universidade.

- Mobilização e Divulgação Científica para os participantes - os docentes e estudantes representantes das escolas participaram de discussão interdisciplinar sobre os problemas atuais relacionados com a sustentabilidade, onde puderam ter contato com tecnologias da sustentabilidade que poderão ser implantadas em suas próprias casas ou escolas. Assim, os docentes e estudantes poderão levar os conhecimentos adquiridos e desenvolver as práticas e tecnologias abordadas nas escolas, utilizando-as como ferramenta de Educação Ambiental e Ensino de Ciências.

- Capacitação e sensibilização ambiental dos estudantes - além de conhecer e aprender sobre as tecnologias da sustentabilidade, os estudantes foram capacitados a detectar problemas ambientais e orientados a desenvolver pensamento crítico com relação a esses problemas, na tentativa de formar sujeitos mais participativos socialmente. Assim, nota-se que o evento não foi apenas para avaliação e premiação, pois os estudantes passaram por um processo de aprendizagem enriquecedor, quando se tornaram disseminadores dos conhecimentos adquiridos e de ações socioambientais nas suas escolas. 
- Estímulo de estudantes ao Campo das Ciências - a aproximação dos estudantes das escolas com a Universidade e com outros estudantes de Ciências, além do contado com as tecnologias da sustentabilidade, serviram para despertar vocações científicas e incentiválos a seguir futuras carreiras científicas e tecnológicas. As fases presenciais na Universidade permitiram, ainda, o desenvolvimento de habilidades importantes nos estudantes, como criatividade, inventividade e capacidade de trabalho em equipe.

- Melhoria do processo de ensino-aprendizagem do ensino de ciências - a prática de uso das tecnologias da sustentabilidade para o Ensino Contextualizado de Ciências (Biologia, Física, Química) poderá ser utilizado na melhoria do processo de ensino aprendizagem nas escolas, o qual poderá ser disseminado em oficinas pedagógicas futuras.

- Consolidação do Modelo de Sustentabilidade da UFSB - Em destaque, nota-se a importância da Olimpíada para a construção e consolidação do Modelo Institucional de Sustentabilidade da UFSB, que prevê a criação de um programa permanente de promoção de práticas de sustentabilidade.

\section{CONCLUSÕES}

A I Olimpíada de Sustentabilidade do Sul da Bahia contou com a participação de 10 escolas de Ensino Básico da região. Atingiu o objetivo principal de despertar e estimular o interesse de estudantes da região ao estudo do Campo das Ciências a partir de atividades didáticas relacionados com a Sustentabilidade. Além de identificar jovens talentos no estudo dos conhecimentos científicos e tecnológicos envolvidos no Campo das Ciências, para que possam seguir futuras carreiras científicas e tecnológicas, as atividades do evento permitiram desenvolver a criatividade, a inventividade e o trabalho em equipe de estudantes e professores, além do despertar de vocações científicas.

\section{Agradecimentos}

Os autores agradecem à Fundação de Amparo à Pesquisa do Estado da Bahia (FAPESB) pelo auxílio financeiro ao evento através do Edital FAPESB n 05/2012 - OLIMPÍADAS DE CIÊNCIAS, com o projeto I Olimpíada de Sustentabilidade do Sul da Bahia.

\section{REFERÊNCIAS}

BARBOSA, E. F.; MOURA, D. G. Metodologias Ativas de Aprendizagem no Ensino de Engenharia. In: XIII International Conference on Engineering and Technology Education, 2014. Anais. Portugal, 2014.

CIANCIARDI, G. A Casa Ecológica. Vinhedo: Editora Horizonte, 2014.

CORBELLA, O; YANNAS, S. Em busca de uma arquitetura sustentável para os trópicos: conforto ambiental. São Paulo: Editora Revan, 2009.

CUSTÓDIO, R.S. Energia Éólica Para Produção de Energia Elétrica. Rio de Janeiro, Editora Synergia, 2013.

DAVIS, M. Tratamento de Águas Para Abastecimento e Residuárias - Princípios e Práticas. Rio de Janeiro: Editora Elsevier, 2016. 
"Os desafios para formar hoje o engenheiro do amanhã"

DOURADO, J.; BELIZÁRIO, F.; PAULINO, A. Escolas Sustentáveis. São Paulo: Editora Oficina de Textos, 2015.

JUNIOR, E.G. TEDxAmazônia - Edgard Gouveia Jr. lembra que somos mais fortes do que parece. Disponível em: https://youtu.be/24JR3cFhZng. Acesso em: 30 jan. 2020.

KEELER, M. \& BURKE, B. Projeto de Edificações Sustentáveis. Porto Alegre: Editora Bookman, 2010.

KOWALTOWSKI, D.C.C.K. Arquitetura Escolar - o Projeto do Ambiente de Ensino. São Paulo: Editora Oficina de Textos, 2011.

MANCUSO, P.C.S; SANTOS, M.F. Reúso de Água. Barueri: Editora Manole, 2003.

TOMAZ,P. Aproveitamento de Água de Chuva. São Paulo: Editora Navegar, 2003..

VILlalVA, M.G. Energia Solar Fotovotáica: Conceitos e Aplicações. São Paulo: Editora Érica, 2015.

\section{FIRST SUSTAINABILITY OLYMPICS OF THE SOUTH OF BAHIA}

Abstract: The First Sustainability Olympics of the South of Bahia had as its general objective the dissemination and popularization of Science and Technology for students of Basic Education in the South of Bahia, especially in the municipalities served by the University Colleges of UFSB, as a way of stimulating them to study the science field from an interdisciplinary theme relevant to contemporary problems, Sustainability. The activities were carried out in three phases: i) theoretical evaluation in schools, which served to select teams of students from schools for the phases carried out at the University; ii) experimental activity at the University, where students learned about sustainability practices and technologies from a sustainable house; and iii) collaborative gymkhana at the University, where students participated in team dynamics for training and environmental awareness. The event was attended by 312 students from 10 schools in the first phase; in this phase, five schools had their teams of five students selected for the phases at the University. In the second and third phases, the winners of the Olympics were defined according to the scores obtained in the experimental and practical activities developed at the University. It should be noted that the phases carried out at the University served to stimulate the creativity and inventiveness of students and teachers, the awakening of scientific vocations and the cooperation bonds between teams of students and teachers.

Keywords: Basic education, Educational technology, Scientific Olympics. 